\title{
Oral Desensitization to Penicillin for the Treatment of Pregnant Women with Syphilis: A Successful Program
}

\section{Dessensibilização oral à penicilina para o tratamento da sifilis na gestação: um exemplo de experiência bem-sucedida} \author{
Vicente Sperb Antonello ${ }^{1,5}$ \\ ${ }^{1}$ Department of Prevention and Infection Control, Hospital Fêmina, \\ Porto Alegre, RS, Brazil \\ 2 Post-graduate Program in Obstetrics and Gynecology, Universidade \\ Federal do Rio Grande do Sul, Porto Alegre, RS, Brazil \\ ${ }^{3}$ Department of STDs and AIDS, Porto Alegre, RS, Brazil \\ ${ }^{4}$ Department of Gynecology and Obstetrics, Hospital Fêmina, Porto \\ Alegre, RS, Brazil \\ ${ }^{5}$ Graduate Program of Medicine, Unisinos, São Leopoldo, RS, Brazil
}

Jéssica Dallé ${ }^{1,2}$ Mauro Cunha Ramos ${ }^{3}$ Mirela Foresti Jimenez ${ }^{1,4}$ Fernanda Garcia Escobar

\author{
Address for correspondence Jessica Dallé, Hospital Fêmina, \\ Universidade Federal do Rio Grande do Sul, Rua Mostardeiro, 17, \\ Moinhos de Vento, Porto Alegre, RS 91430-001, Brasil \\ (e-mail: jessicadalle@gmail.com).
}

Rev Bras Ginecol Obstet 2018;40:43-46.

\begin{abstract}
Keywords

- syphilis

- pregnant women

- penicillins

- hypersensitivity
\end{abstract}

Resumo
Gestational syphilis is a prevalent disease in Brazil and other low and medium income countries. Desensitization to penicillin is recommended for pregnant women with syphilis who are allergic to $\beta$-lactams. This is a descriptive study utilizing outpatient medical records from 2011 to 2015 from a mother and child hospital that is part of the national healthcare system in the South of Brazil, which performs an average of 3,600 birth assistances per year. All cases of pregnant women with syphilis and presumptive diagnosis of $\beta$-lactam allergy during the study period were included. The patients referred for desensitization originated from the hospital prenatal care service, as well as from municipal/state antenatal care services. Oral desensitization was performed in the obstetric emergency room, and adult and pediatric intensive care units were available at all times. Ten patients underwent desensitization during the period of study. Personal history of urticaria was the most common reaction that demanded desensitization. All patients tolerated the procedure well, and showed no adverse reactions. We report a successful program of oral desensitization. None of the patients presented adverse reactions or complications, a fact that corroborates the feasibility and safety of the desensitization protocol. Oral administration of penicillin comes at a low cost, and optimizes the use of time and resources.

A sífilis gestacional é uma doença prevalente no Brasil e em outros países de baixa e média renda. A dessensibilização à penicilina é recomendada para mulheres grávidas com sífilis que são alérgicas a $\beta$-lactâmicos. Este é um estudo descritivo que utiliza received

April 4, 2017

accepted

July 18, 2017

published online

August 31, 2017
DOI https://doi.org/

10.1055/s-0037-1606274. ISSN 0100-7203.
Copyright $(2018$ by Thieme Revinter

Publicações Ltda, Rio de Janeiro, Brazil
License terms

(c) (i) $\ominus$ (\$) 


\author{
Palavras-chave \\ - sífilis \\ - gestantes \\ - penicilinas \\ - hipersensibilidade
}

registros médicos de 2011 a 2015 de um hospital público materno-fetal do Sul do Brasil com média de 3.600 partos anuais. Foram incluídos todos os casos de gestantes com sífilis e diagnóstico presuntivo de alergia a $\beta$-lactâmicos durante o período de estudo. As pacientes encaminhadas para dessensibilização originaram-se do serviço pré-natal hospitalar internamente, bem como dos serviços municipais e estaduais de atendimento pré-natal. A dessensibilização oral foi realizada na sala de emergência obstétrica, e a unidade de terapia intensiva estava disponível em todos os momentos para o atendimento de possíveis intercorrências. Dez pacientes foram submetidas à dessensibilização durante o período estudado. História pessoal de urticária foi a reação mais comum que exigiu dessensibilização à penicilina. Todas as pacientes toleraram bem o procedimento, e não mostraram reações adversas. Relatamos no presente manuscrito um programa bem-sucedido de dessensibilização oral à penicilina. Nenhuma das pacientes apresentou reações adversas ou complicações, corroborando a viabilidade e segurança do protocolo de dessensibilização. A administração oral de penicilina tem baixo custo, e otimiza o uso de tempo e recursos para o tratamento adequado de sífilis gestacional no cenário apresentado.

\section{Introduction}

Gestational syphilis is a prevalent disease in Brazil and other low and medium income countries. ${ }^{1}$ It causes obstetric adverse events in the majority of untreated women. ${ }^{2}$ Paradoxically, in a time of increasing antimicrobial resistance and higher demand for expensive drugs, penicillin remains the one drug considered adequate for the treatment of pregnant women and for the prevention of congenital syphilis. ${ }^{3,4}$ In a systematic review that included almost 3.5 million patients, the incidence of anaphylaxis among individuals treated with penicillin was of 0 to 3 per 100,000 and no serious adverse reactions occurred among the 1,244 pregnant women included in the study. Nonetheless, true allergies to $\beta$-lactams exist and are a matter of concern, being self-reported by up to $20 \%$ of individuals. ${ }^{4}$

Desensitization to penicillin is recommended for pregnant women with syphilis who are allergic to $\beta$-lactams. ${ }^{5,6}$ The present study aimed to report a program of oral desensitization for women with gestational syphilis and history of an allergy to penicillin in a public mother and child tertiary hospital in the city of Porto Alegre, capital of the state of Rio Grande do Sul, Southern Brazil.

\section{Methods}

This is a descriptive study with data gathered from medical records of a mother and child teaching hospital from 2011 to 2015. The hospital is part of the Brazilian Unified Healthcare System (SUS, in the Portuguese acronym), and provides free tertiary care. An average of 3,600 birth assistances are performed per year there. All cases of pregnant women with syphilis and a diagnosis of allergy, based on personal history of skin eruption after using $\beta$-lactams during the study period, were included. The study was approved by the Institutional Review Board (protocol number 47914815.2.0000.5530). All data analyzed were anonymized. The patients referred for desensitization originated from the hospital prenatal care service, as well as, municipal or state antenatal care networks.
Once a presumptive diagnosis of penicillin allergy had been established, oral desensitization was performed in accordance with the protocol described by Wendel et al. ${ }^{7}$ The procedure of desensitization occurred in the obstetric emergency room, and it was monitored by obstetrics and gynecology practitioners. Peripheral venous access was established before the procedure, and was maintained until its completion. Clinical parameters were used to monitor the patients and obstetric events during the entire procedure. Adult and pediatric intensive care units were available at all times.

Penicillin V (phenoxymethylpenicillin) was used in oral solutions of $1,000,10,000$, and 80,000 units $/ \mathrm{mL}$ (-Table 1).

Table 1 Oral-desensitization to penicillin allergy protocol

\begin{tabular}{|l|l|l|l|l|}
\hline $\begin{array}{l}\text { Penicillin V } \\
\text { suspension } \\
\text { dose }\end{array}$ & $\begin{array}{l}\text { Amount } \\
\text { (units/mL) }\end{array}$ & $\mathrm{mL}$ & Units & $\begin{array}{l}\text { Cumulative } \\
\text { dose (units) }\end{array}$ \\
\hline 1 & 1,000 & 0.1 & 100 & 100 \\
\hline 2 & 1,000 & 0.2 & 200 & 300 \\
\hline 3 & 1,000 & 0.4 & 400 & 700 \\
\hline 4 & 1,000 & 0.8 & 800 & 1,500 \\
\hline 5 & 1,000 & 1.6 & 1,600 & 3,100 \\
\hline 6 & 1,000 & 3.2 & 3,200 & 6,300 \\
\hline 7 & 1,000 & 6.4 & 6,400 & 12,700 \\
\hline 8 & 10,000 & 1.2 & 12,000 & 24,700 \\
\hline 9 & 10,000 & 2.4 & 24,000 & 48,700 \\
\hline 10 & 10,000 & 4.8 & 48,000 & 96,700 \\
\hline 11 & 10,000 & 1.0 & 80,000 & 176,700 \\
\hline 12 & 80,000 & 2.0 & 160,000 & 336,700 \\
\hline 13 & 80,000 & 4.0 & 320,000 & 656,700 \\
\hline 14 & 80,000 & 8.0 & 640,000 & $1,296,700$ \\
\hline
\end{tabular}

Note: Observation period: 30 minutes before parenteral administration of penicillin; interval between doses: 15 minutes; elapsed time, 3 hours and 45 minutes; cumulative dose, 1.3 million units. ${ }^{7}$ 
The initial dose was of 100 units/mL. It was doubled every 15 minutes, until a final dose of $1,296,700$ units/mL was reached. No preventive allergy medication was used. Thirty minutes after the end of the desensitization procedure, an intramuscular injection of benzathine penicillin $(2,400,000$ units $/ \mathrm{mL})$ was administered, and the patients were monitored for at least 1 hour. Additional doses of benzathine penicillin $(2,400,000$ units $/ \mathrm{mL})$ were prescribed according to the clinical stage, and administered always at hospitals, either locally or in the patients' city of residence.

\section{Results}

Ten patients underwent desensitization during the period of study. The average age of the patients was 27 years (ranging from 21 to 33 years). Four patients were users of crack cocaine, and one was a tobacco smoker. No other comorbidities were reported. Six patients were residents of the city of Porto Alegre. The remaining four resided in other cities, with a distance ranging from 16 to $491 \mathrm{~km}$. Personal history of urticaria was the most common reaction that demanded desensitization. It occurred in seven patients, five of them during childhood. Regarding the last three patients, one reported facial edema, the other reported respiratory distress and facial edema, and the last one could not characterize the type of skin eruption occurred after the administration of penicillin.

Total 5 patients had 6 or more antenatal care visits, 3 had less than 6 , and 2 had no information regarding the number of visits. All patients were diagnosed during the current pregnancy at stages of late latent syphilis or latent syphilis of unknown duration. The gestational age at the time of the desensitization varied from 6 to 36 weeks - 1 patient was in the first trimester of gestation, and 4 were in the second. The 5 remaining patients, who were treated while they were in the third trimester, lived outside Porto Alegre. Five patients completed the treatment 30 days or more before delivery, 4 completed the treatment less than 30 days before delivery, and 1 received incomplete treatment. Total 9 patients underwent the desensitization procedure before the first dose of benzathine penicillin, and 1 patient had an urticarial reaction after the first injection, which was administered at a primary care antenatal center; therefore, her desensitization occurred before the second dose. One patient, who had abandoned the treatment after the first dose, was submitted to a second desensitization before initiating the second series of injections.

All patients tolerated the procedure well, and showed no adverse reactions or complications. Nine of them were followed-up until the completion of the treatment, with no complications observed.

\section{Discussion}

The present study reported a successful program of oral desensitization of women with syphilis and presumptive diagnosis of allergy to penicillin. None of the patients presented any adverse reactions or complications during the desensitization, a fact that can be viewed as a corrobora- tion of the feasibility and safety of the desensitization protocol, which was previously demonstrated. ${ }^{7-9}$ The oral administration of penicillin $\mathrm{V}$ facilitates the execution and optimizes the use of time and resources. Moreover its cost is very low: USD 2.80 per patient on average. The drug is provided by the SUS, and that enables its use in any region of Brazil. In a previous study, Chisholm et $\mathrm{al}^{6}$ also emphasized the lower cost of the oral procedure in comparison to other forms of desensitization, such as the more expensive and complex intravenous administration. We acknowledge that basing the diagnosis of penicillin allergy exclusively on clinical history, without performing skin testing, may lead to overdiagnosis and unnecessary desensitization; but, in practical terms, the unavailability of tests could prevent timely treatment in settings in which the tests and skills for performing them are not available.

The occurrence of congenital syphilis has been considered an indicator of the quality of the antenatal care. ${ }^{10-13}$ In spite of the increasing coverage of antenatal care in Brazil, and the availability of rapid tests for syphilis in the primary antenatal care system, the disease is far from being under control. The Brazilian Ministry of Health recommends the use of rapid tests and the immediate use of benzathine penicillin in primary antenatal services when needed. It is known that the benefits of using penicillin to treat pregnant women with syphilis surpasses by far its risks; however, it is also known that the rare event of allergy to penicillin can have severe consequences, and must be dealt with accordingly. ${ }^{1}$

We ultimately intend to reinforce that the safety and feasibility of oral desensitization to penicillin depends on the availability of means and skills to address possible complications. ${ }^{5,8}$ If we consider the low numbers of referrals, coming from such a large population and geographic area, we recommend the creation of reference centers. Among our cases, however, almost half the group travelled to obtain the procedure, and this indicates the need of reorganization of the health system. These cases should have been treated closer to their places of residence. Based on the evidence that patients travel long distances, one could hypothesize that there is a misconception that desensitization to penicillin is a difficult protocol to implement. This may hinder the patients' access to the desensitization procedure and timely treatment. We hope our findings encourage healthcare professionals to consider the organization of similar services, in order to effectively prevent cases of congenital syphilis.

Conflicts of Interest

The authors have no conflicts of interest to disclose.

\section{References}

1 Domingues RMSM, Szwarcwald CL, Souza Junior PR, Leal MdoC. Prevalence of syphilis in pregnancy and prenatal syphilis testing in Brazil: birth in Brazil study. Rev Saude Publica 2014;48(05): 766-774

2 Newman L, Kamb M, Hawkes S, et al. Global estimates of syphilis in pregnancy and associated adverse outcomes: analysis of multinational antenatal surveillance data. PLoS Med 2013;10(02): e1001396 
3 Wendel GD Jr, Sheffield JS, Hollier LM, Hill JB, Ramsey PS, Sánchez PJ. Treatment of syphilis in pregnancy and prevention of congenital syphilis. Clin Infect Dis 2002;35(Suppl 2):S200-S209

4 Galvao TF, Silva MT, Serruya SJ, et al. Safety of benzathine penicillin for preventing congenital syphilis: a systematic review. PLoS One 2013;8(02):e56463

5 Mirakian R, Leech SC, Krishna MT, et al; Standards of Care Committee of the British Society for Allergy and Clinical Immunology. Management of allergy to penicillins and other betalactams. Clin Exp Allergy 2015;45(02):300-327

6 Chisholm CA, Katz VL, McDonald TL, Bowes WA Jr. Penicillin desensitization in the treatment of syphilis during pregnancy. Am J Perinatol 1997;14(09):553-554

7 Wendel GD Jr, Stark BJ, Jamison RB, Molina RD, Sullivan TJ. Penicillin allergy and desensitization in serious infections during pregnancy. N Engl J Med 1985;312(19):1229-1232
8 Soriano V, Niveiro E, Fernández J, Castelló JV, González P. Successful desensitization to penicillin after diagnostic reassessment. Allergol Immunopathol (Madr) 2003;31(02):94-96

9 Ziaya PR, Hankins GD, Gilstrap LC III, Halsey AB. Intravenous penicillin desensitization and treatment during pregnancy. JAMA 1986;256(18):2561-2562

10 Boletim Epidemiológico: Sífilis. Brasília, DF: Ministério da Saúde; 2015

11 Ximenes IPE, Moura ERF, Freitas GL, Oliveira NC. Incidência e controle da sífilis congênita no Ceará. Rev Rene 2008;9(03):74-80

12 Domingues RM, Saracen V, Hartz ZM, Leal MC. Congenital syphilis: a sentinel event in antenatal care quality. Rev Saude Publica 2013;47(01):147-157

13 Campos AL, Araújo MA, Melo SP, Andrade RF, Gonçalves ML. [Syphilis in parturients: aspects related to the sex partner]. Rev Bras Ginecol Obstet 2012;34(09):397-402 